\title{
Safety, usability, and independence for wheelchair-seated drivers and front-row passengers of private vehicles: A qualitative research study
}

\author{
Linda van Roosmalen, PhD; ${ }^{1^{*}}$ Nichole Ritchie Orton, $\mathbf{M S} ;^{\mathbf{2}}$ Lawrence Schneider, $\mathbf{P h D}{ }^{\mathbf{2}}$ \\ ${ }^{1}$ Department of Rehabilitation Science and Technology, University of Pittsburgh, Pittsburgh, PA; ${ }^{2}$ Biosciences Division, \\ University of Michigan Transportation Research Institute, Ann Arbor, MI
}

\begin{abstract}
A survey and observational study was conducted with 29 people who remain seated in their wheelchair when driving (21) or riding as a front-row passenger (8) in their personal vehicle. Each subject was observed and surveyed in their own personal vehicle that has been modified for use by occupants seated in wheelchairs. Our survey obtained responses on issues related to occupant restraint (seat belt) system usage, wheelchair securement device usage, and perception of personal safety while riding in a vehicle. Usability and accessibility issues related to seat belt and automated (docking) wheelchair securement technology were revealed, suggesting that wheelchairseated occupants travel with a higher risk of serious injury in vehicle crashes than front-row occupants seated in original equipment manufacturer (OEM) vehicle seats and using OEM seat belts. Study results also indicate the need for improved torso support for many wheelchair-seated drivers to maintain a posture that allows for effective vehicle control. Study results demonstrate the need for innovative passive restraint technologies that provide postural support during normal vehicle operation and improved occupant restraint during crash conditions for people who drive while seated in their wheelchairs.
\end{abstract}

Key words: driving, injury, occupant restraint, postural support, safety, seat belt, securement, vehicle, wheelchair, wheelchairseated driver.

\section{INTRODUCTION}

\section{Background}

According to the Bureau of Transportation Statistics, over 95 percent of U.S. adults drive or ride in a personal motor vehicle, but for adults with disabilities, this percentage is reduced to 83 percent [1]. Additionally, this report states that about 1.9 million people with disabilities never leave their homes, of which about 528,000 never leave their homes because of transportation difficulties [1]. Personal motor vehicles are used to get to work, seek medical care, go shopping, and participate in social activities. It has also been documented that 85 percent of all adults use a personal vehicle to get to their place of employment compared with 66 percent of adults with disabilities [1]. Findings from a survey conducted among 101 mobility equipment dealers indicate that over 10,000 vehicles are modified each year for use by people with disabilities. Of these vehicles, 71 percent are full-size vans or minivans

\footnotetext{
Abbreviations: $\mathrm{OEM}=$ original equipment manufacturer, RESNA = Rehabilitation Engineering and Assistive Technology Society of North America.

*Address all correspondence to Linda van Roosmalen, PhD; 139 Shannon Heights Dr, Verona, PA 15147; 412-4018194. Email: Linda@LINC-Design.com http://dx.doi.org/10.1682/JRRD.2011.11.0217
} 
$(7,196)$, of which about 60 percent are modified to accommodate drivers with disabilities and 40 percent are modified to accommodate passengers with disabilities [2].

To ensure drivers and passengers seated in wheelchairs remain stable during turns and stops and provide effective restraint during crash situations, a crashworthy wheelchair securement system consisting either of an automated docking securement device (primarily for drivers who require independent use of their vehicle) or a four-point, strap-type tiedown system (primarily for passengers) is commonly prescribed and installed. Examples of commercial crashtested docking-type securement systems that allow for independent wheelchair securement and that comply with Society of Automotive Engineers Recommended Practice J2249 [3] include the EZ-Lock (EZ-Lock Inc; Baton Rouge, Louisiana), the QLK (Q'Straint Worldwide; Ft. Lauderdale, Florida), the Dock 'N' Lock (Freedom Sciences; Green Lane, Pennsylvania), and the Permolock (Permobil Inc; Lebanon, Tennessee). All of these securement systems except the Permolock are intended for use with a range of wheelchair models but require the addition of wheelchair-specific securement adaptors to each wheelchair model. In addition, it is important to crash test the wheelchair with the specific securement system to ensure wheelchair crashworthiness with each securement device.

When a driver or front-row passenger stays seated in his or her wheelchair, the original equipment manufacturer (OEM) seat needs to be removed from the vehicle. In general, this means that the OEM seat belt buckle receptacle (originally mounted to the OEM seat) is also removed and must be replaced by a matching buckle receptacle and fixture to be effectively used by a wheelchair user. To ensure effective wheelchair-occupant crash protection, a well-positioned belt restraint system consisting of a threepoint lap/shoulder-belt restraint is needed. For front-row wheelchair-seated occupants, front-impact airbags offer additional restraint and protection, particularly for the head and chest of belt-restrained occupants in a frontal crash. To reduce the risk of injury from seat belt loading in a crash, it is critical that the shoulder and lap belts are correctly positioned across the bony parts of the shoulder and pelvis, respectively [3].

To be fully independent, drivers seated in wheelchairs must be able to use a properly fitted belt-restraint system without the assistance of another person. Reaching for, buckling, and releasing the buckle of standard belt-type occupant restraints can be a difficult or impossible task for many drivers seated in wheelchairs because of reduced manual dexterity and upper-limb range of motion, as well as challenges encountered routing the belts around or through wheelchair components and/or vehicle controls to achieve proper belt fit [4]. Belt restraints that do not fit properly generally are not very effective in moderate-tosevere frontal collisions and may even be the source of serious or fatal injuries [5-8].

The American National Standards Institute/Rehabilitation Engineering and Assistive Technology Society of North America (RESNA) transportation safety wheelchair industry standard known as WC19 [9] includes a method for rating a wheelchair for how well it accommodates the effective and proper use of vehicle-anchored belt restraints. As of this writing, the standard applies a single rating that is designed to evaluate the ease of use, positioning, and location of shoulder and lap belts on a wheelchair occupant. However, this belt rating currently only applies to situations in which caregivers assist wheelchair-seated passengers with the belt restraint system. A wheelchair with arm supports that are closed at the front may receive a high rating for seat belt accommodation when applied by a caregiver but will generally not allow for proper belt fit for a driver seated in a wheelchair with limited upper-limb function who needs a belt restraint that requires little to no action by the occupant or his or her caregiver (i.e., a passive belt restraint system) [10].

Also, compliance of a wheelchair with WC19 does not mean that a wheelchair has been crash tested for docking securement. WC19 requires that a wheelchair is successfully crash tested when secured by a four-point, strap-type tiedown system. It does not, however, require that wheelchairs are crash tested for docking securement, for which the load paths on the wheelchair frame will be completely different in a frontal crash than when the wheelchair is secured by a four-point, strap-type tiedown. While WC19 allows for testing wheelchairs when secured by a commercially available docking securement device and fitted with the appropriate securement adaptor, only a selection of commercial wheelchairs have been crash tested with custom brackets for safe use with an automatic docking securement.

\section{Objectives}

This study is part of a larger research study on drivers and front-row passengers seated in wheelchairs while traveling in personal vehicles. The first objective was to observe wheelchair-seated volunteers using their own vehicles and to document the difficulties encountered 
when entering and exiting the vehicles and using wheelchair securement and occupant-restraint systems. The second objective was to survey study participants to determine their perceived level of rider safety and independence. The third objective was to solicit and document suggestions for improving the private-vehicle environment for wheelchair-seated drivers and front-row passengers.

\section{METHODS}

We recruited 29 adult individuals who stay seated in their wheelchairs when riding as a passenger or driver in a personally licensed vehicle, 11 from the Pittsburgh, Pennsylvania, area and 18 from the Ann Arbor, Michigan, area, through the distribution of flyers and by posting advertisements in newspapers. We observed participants while entering their vehicles, securing their wheelchairs, and positioning their belt restraints to prepare for driving or riding. We also observed them stowing their seat belts and exiting their vehicles. We used digital videos and photographs to document driver and passenger positioning inside their vehicles and to document each participant's wheelchair, restraint system, and driving controls (when applicable). An investigator surveyed participants using a set of questions asked verbally with regard to their vehicle and wheelchair configurations and their personal perception of safety and independent use of their vehicles' safety equipment.

\section{RESULTS}

Of the 29 study participants, 21 were drivers and 8 were vehicle passengers. All passengers sat in the front-row passenger station in their vehicles. Of the 21 drivers, 15 stated that they sometimes also travel as passengers in their private vehicles. Of these 15 participants, 12 would sit in the front-row passenger location and 3 would sit behind the driver station in the second row of the vehicle.

Table 1 lists the demographics and rider characteristics of the participant group. Participants were, on average, $50.3 \mathrm{yr}$ old (47.1 yr old for drivers and $58.5 \mathrm{yr}$ old for passengers). The average number of years participants had been using a wheelchair on a permanent basis was 20.4, and on average, drivers had used a modified vehicle for $14.2 \mathrm{yr}$ and passengers for $8.8 \mathrm{yr}$. Drivers used their vehicles on average 5.5 days/week for 1.4 hours/day, and
Table 1.

Participant demographics.

\begin{tabular}{lccc}
\hline General Information & Combined & Driver & Passenger \\
\hline Participants (n) & 29 & 21 & 8 \\
Age (yr) & 50.3 & 47.1 & 58.5 \\
Wheelchair Use (yr) & 20.4 & 21.7 & 16.9 \\
Private Vehicle Use (yr) & 12.7 & 14.2 & 8.8 \\
Ride Frequency (d/wk) & 4.8 & 5.5 & 3.0 \\
Ride Duration (h/d) & 1.4 & 1.4 & 1.3 \\
\hline \hline
\end{tabular}

passengers used their vehicles on average 3.0 days/week for about 1.3 hours/day.

Table 2 lists the vehicles and wheelchairs used by each study participant. Of the vehicles, 21 were purchased new and 8 were preowned. Of the wheelchairs, 22 were equipped with docking securement adaptors, which allow for independent and quick wheelchair securement inside the vehicle using a docking securement device installed on the vehicle floor. Three participants had wheelchairs that were not modified for securement inside a motor vehicle.

Of the 21 drivers, 16 used power wheelchairs that were equipped with docking-securement adaptive hardware. Four drivers used manual wheelchairs with power assist, of which three had docking securement adaptors installed on their wheelchair. Eight passengers used power wheelchairs, of which three were equipped with docking securement adaptors; four passengers used four-point, strap-type tiedowns for wheelchair securement; and one was not modified for securement inside a motor vehicle. Table 3 summarizes the numbers of new and preowned vehicles, wheelchair-securement types, and wheelchair types for study participants.

Table 4 lists information on the wheelchair equipment across study participants. Participants' wheelchairs varied with regard to common features such as rear head supports, postural pelvic belts, arm supports, and foot supports. All but one wheelchair had arm supports, and most of the wheelchairs had foot supports. Less than half of the participants had a rear head support on their wheelchair, with most head supports being on the power wheelchairs.

\section{Vehicle Configurations}

Table 5 summarizes the different modifications made to participants' vehicles for drivers and passengers. For drivers seated in wheelchairs, all of the OEM seats had been removed and after-market equipment (including a buckle receptacle on a stalk mounted to a floor track) was 
JRRD, Volume 50, Number 2, 2013

Table 2.

Vehicles and wheelchairs used by participants.

\begin{tabular}{|c|c|c|}
\hline Participant & Vehicle & Wheelchair \\
\hline \multirow[t]{15}{*}{ Drivers } & 2007 Chevrolet Uplander (N) & Quickie 2 with power assist (PA/D) \\
\hline & 2005 Plymouth Montana (N) & Invacare Storm TDX3 (P/D) \\
\hline & 2002 Dodge Grand Caravan Sport (PO) & TiLite Evo with Emotion power assist (PA/D) \\
\hline & 2002 Ford Econoline E150 (N) & Quickie P-220 (P/D) \\
\hline & 1998 unknown (PO) & Quickie V-521 (P/D) \\
\hline & 2000 Ford E150 (N) & TiLite Evo with Emotion power assist (PA/D) \\
\hline & 2004 Dodge Caravan (Entervan) (N) & Permobile C300 (P/D) \\
\hline & 1997 GMC Pickup Truck (N) & Quickie GP with Xtender power assist (PA) ${ }^{*}$ \\
\hline & 2006 Toyota Sienna (N) & Permobil C500 Stander (P/D) \\
\hline & 2005 Toyota Sienna (N) & Invacare Action Arrow Storm (P/D) \\
\hline & 2004 Toyota Sienna XLE (N) & Invacare Arrow (P/D) \\
\hline & 2001 Ford Econoline (N) & Permobil Chairman (P/D) \\
\hline & 2006 Toyota Sienna (N) & Invacare Ranger 2 (P/D) \\
\hline & 2005 Toyota Sienna (N) & C500 Permobil (P) ${ }^{*}$ \\
\hline & Ford Club Wagon $(\mathrm{N})^{\dagger}$ & Quickie P200 (P/D) \\
\hline \multirow[t]{6}{*}{ Passengers } & 1999 Dodge Caravan (PO) & Invacare Torque SP (P/S) \\
\hline & 2005 Chrysler Town \& Country (Entervan) (N) & Invacare Storm TDX5 (P/D) \\
\hline & 2002 Chrysler Town \& Country (Entervan) (N) & Invacare Storm TDX5 (P/D) \\
\hline & 1997 Chrysler Town \& Country (Entervan) (PO) & Pride Mobility Quantum $600(\mathrm{P})^{*}$ \\
\hline & 2003 Dodge Grand Caravan (PO) & Pride Mobility Jazzy 1122 (P/S) \\
\hline & 2003 Chevrolet Venture (PO) & Permobil C300 (P/S) \\
\hline
\end{tabular}

Table 3.

Summary table for study participants.

\begin{tabular}{lr}
\hline \multicolumn{1}{c}{ Characteristic } & $\boldsymbol{n}$ \\
\hline New Vehicle & 21 \\
Preowned Vehicle & 8 \\
Drivers in Power Wheelchair & 17 \\
Drivers in Power-Assist Wheelchair & 4 \\
Passengers in Power Wheelchair & 8 \\
Passengers in Manual Wheelchair & 0 \\
Lowered Floor & 15 \\
Voice-activated Secondary Controls & 4 \\
\hline
\end{tabular}

installed so that the vehicle seat belt could be used, and in one case the driver used the seat belt buckle receptacle on the passenger seat. Also, seven drivers reported they had the steering-wheel airbag removed or deactivated. All but
Table 4.

Wheelchair add-on equipment used by study participants (n).

\begin{tabular}{lccc}
\hline Wheelchair Equipment & Combined & Driver & Passenger \\
\hline Rear Headrest & 13 & 5 & 8 \\
Pelvic Support & 12 & 6 & 6 \\
Chest Support & 7 & 6 & 1 \\
Lateral Support & 11 & 7 & 4 \\
Tray & 0 & 0 & 0 \\
Oxygen Tank & 0 & 0 & 0 \\
Foot Supports & 25 & 18 & 7 \\
Armrests & 28 & 20 & 8 \\
\hline \hline
\end{tabular}

one driver's vehicle had a docking securement device installed in the driver station, but two drivers operated their vehicle without using a securement system. One of these individuals did not have the docking securement adaptor 
Table 5.

Vehicle equipment installed and modifications made $(n)$.

\begin{tabular}{|c|c|c|c|}
\hline Vehicle Equipment & Combined & Driver & Passenger \\
\hline Original Vehicle Seat Removed & 29 & 21 & 8 \\
\hline Docking Securement & 22 & 19 & 3 \\
\hline Four-point, Strap-type Tiedown & 4 & 0 & 4 \\
\hline Lift Access & 6 & 6 & 0 \\
\hline Hand-control Gas/Brake Pedal Extensions & - & 13 & - \\
\hline Electronic Hand Controls & - & 8 & - \\
\hline Active Steering-wheel Airbag & - & 14 & - \\
\hline Active Dash-mounted Airbag & - & - & 8 \\
\hline Aftermarket Seat Belt Components for Using Vehicle Seat Belt & 29 & 21 & 8 \\
\hline Original Vehicle Seat Belt with Aftermarket Buckle Receptacle & 19 & 12 & 7 \\
\hline
\end{tabular}

installed on his or her power-assist wheelchair and the other was in the process of getting a new wheelchair with a securement adaptor and docking securement device.

Participants were also asked about their knowledge of safety standards related to using their wheelchair as a seat in a motor vehicle. Of the 29 participants, only 2 were aware of any industry wheelchair safety standards.

Of the 29 participants, 23 used a ramp and 6 used a power lift to enter and exit the vehicle. Of the drivers, 13 used mechanical hand controls to operate gas and brake pedal extensions and steering-wheel assistive devices (i.e., grip enhancers), such as tri-pins or spinner knobs; 8 used electrically powered hand controls; and 1 had adaptive secondary controls installed in his or her vehicle to operate turn signals, windshield wipers, etc. Other modifications that were made to accommodate drivers seated in wheelchairs included an automated control to release the docking securement system; floor seat belt anchorage tracks; a lowered floor (15 participants) to increase head clearance and to provide proper eye height for the driver to see out the windshield; a vehicle kneeling system to reduce floor-to-ground height; a remote control or button for automatic door, ramp, or lift deployment; and a voice-activated system (4 participants) to operate secondary vehicle controls such as temperature controls, wiper blades, and turn signals.

\section{User Perception on Vehicle Use and Safety}

After documenting wheelchair and vehicle configurations, we asked participants about their perceptions regarding the use and safety of their vehicles. We used a 5-point Likert scale to rank participants' answers, where $1=$ very unsafe or not important at all and $5=$ very safe or very important.

We first asked participants about their sense for safety while getting in and out of the vehicle, and while traveling through urban and rural areas. Table 6 indicates that, on average, drivers and passengers felt safe (average score of 4) while getting in their vehicles, while traveling in urban and rural areas, while exiting their vehicle, and about their overall travel. We asked participants how important it is to have an effective seat belt restraint system when they are traveling while seated in their wheelchairs. Drivers reported that it was important to very important (average score of 4.6) and passengers reported it was important (average score of 4.3) to have an effective seat belt system when riding while seated in their wheelchairs (Table 6). However, on average, drivers felt

Table 6.

Participant perception of safety during ingress and egress, during driving, overall, and importance of seat belts, where 1 = don't know, 2 = poor, 3 = could be better, 4 = good, and 5 = excellent.

\begin{tabular}{lccc}
\hline \multicolumn{1}{c}{ User Perception } & Combined & Driver & Passenger \\
\hline Getting in Vehicle & 4.2 & 4.2 & 4.1 \\
Traveling in Urban Areas & 4.0 & 4.0 & 3.9 \\
Traveling in Rural Areas & 4.2 & 4.2 & 4.1 \\
Overall Travel Safety & 3.9 & 4.0 & 3.8 \\
Exiting Vehicle & 4.1 & 4.2 & 3.9 \\
Seat Belt Importance & 4.3 & 4.6 & 4.3 \\
${ }^{*}$ 1 = don't know, 2 = unimportant, 3 = a little important, 4 = important, and 5 = \\
very important.
\end{tabular}


that their level of safety could be better (average score of 3.4) when they rode as passengers seated in their wheelchair in their own vehicle.

\section{Safety System Difficulties}

Participants expressed difficulties when using both the wheelchair securement and seat belt restraint systems. The majority of reported usability issues were related to the wheelchair docking system. Additional issues listed by drivers include problems with wheelchair foot supports getting caught on the docking-securement device or loose carpet, vehicle-seat anchorage pockets preventing easy maneuvering into and out of the wheelchair space and docking securement device, and difficulty lining up the wheelchair to properly engage the bolt on the wheelchair securement adaptor with the docking securement device. From the four participants and their caregivers that used a four-point, strap-type tiedown system, two caregivers indicated that tiedown straps are more difficult to tension when the straps are of the older type that require manual tensioning (rather than the new automatic-locking retractor tiedowns) and another caregiver mentioned that it is difficult to secure the front of the wheelchair because of difficulty reaching for tiedown straps and wheelchair securement points in the (tight) vehicle interior. One caregiver crisscrossed the rear securement straps so that they could be tightened better, and one participant mentioned that it is difficult to keep a wheelchair from rolling over rear tiedown straps and hardware when entering or exiting the vehicle.

\section{Driver Difficulties and Observations}

We observed, documented, and categorized wheelchair securement, occupant restraint, and installation problems of 21 drivers. The numbers in parentheses below indicate the number of drivers that experienced the issue.

\section{Wheelchair Securement System}

- The manual release of the docking system cannot be reached or operated in case of power failure and drivers must rely on their cellular telephones to call for help (19).

- It takes several tries to align and engage the docking system (10).

- The securement bolt on the wheelchair has low ground clearance and catches on rough terrain and obstacles outside the vehicle (6).

- The drivers ride against the docking station structure with their wheelchairs upon entry and need to reposition the wheelchair and retry (4).

\section{Occupant Restraint System}

- The shoulder belt is not snug enough or is too snug (8).

- Drivers cannot rely on the shoulder belt for postural support during vehicle maneuvers, which adds to instability (6).

- The wheelchair joystick interferes with the occupant restraint system (5).

- The wheelchair arm supports interfere with proper placement of the lap belt over the pelvis (4).

For more information, see Figure 1.

\section{Vehicle and System Installation}

- The inboard buckle for the pelvic belt falls on the floor, making it difficult to reach (4).

- The pelvic belt buckle is difficult to reach because the wheelchair arm support and joystick are in the way (5).

- The floor in the vehicle makes maneuvering difficult-i.e., wheels slip on the carpet or get stuck in the empty vehicle-seat anchorage pockets (3).

\section{Passenger Difficulties and Observations}

We observed, documented, and categorized wheelchair securement, occupant restraint, and installation problems of 8 passengers and their caregivers.

\section{Wheelchair Securement System}

- It takes several tries to align and engage the wheelchair with the docking-securement device (3).

- The tiedown straps are difficult to reach and tighten (3).

- The user rides against the docking station structure or tiedown hardware upon entry and needs to reposition the wheelchair and retry (3).

- The bolt on the bottom of the wheelchair for docking securement has low ground clearance and catches on rough terrain and obstacles outside the vehicle (2).

\section{Occupant Restraint System}

- The shoulder belt pulls out due to slow forward movement of the upper torso, adding to passenger instability (3).

- The shoulder belt is not tight enough or is too tight (3).

- The wheelchair arm supports and joystick controller interfere with proper positioning of the seat belt (2).

For more information, see Figure 2.

\section{Seat Belt Donning and Placement}

Drivers either had an active or passive occupant restraint system installed. With an active occupant restraint, 
the driver has to manually route the belt across his or her body and the wheelchair and buckle the belt's latch plate into the buckle receptacle. With a passive occupant restraint, the driver moves forward into a prebuckled shoulder and lap

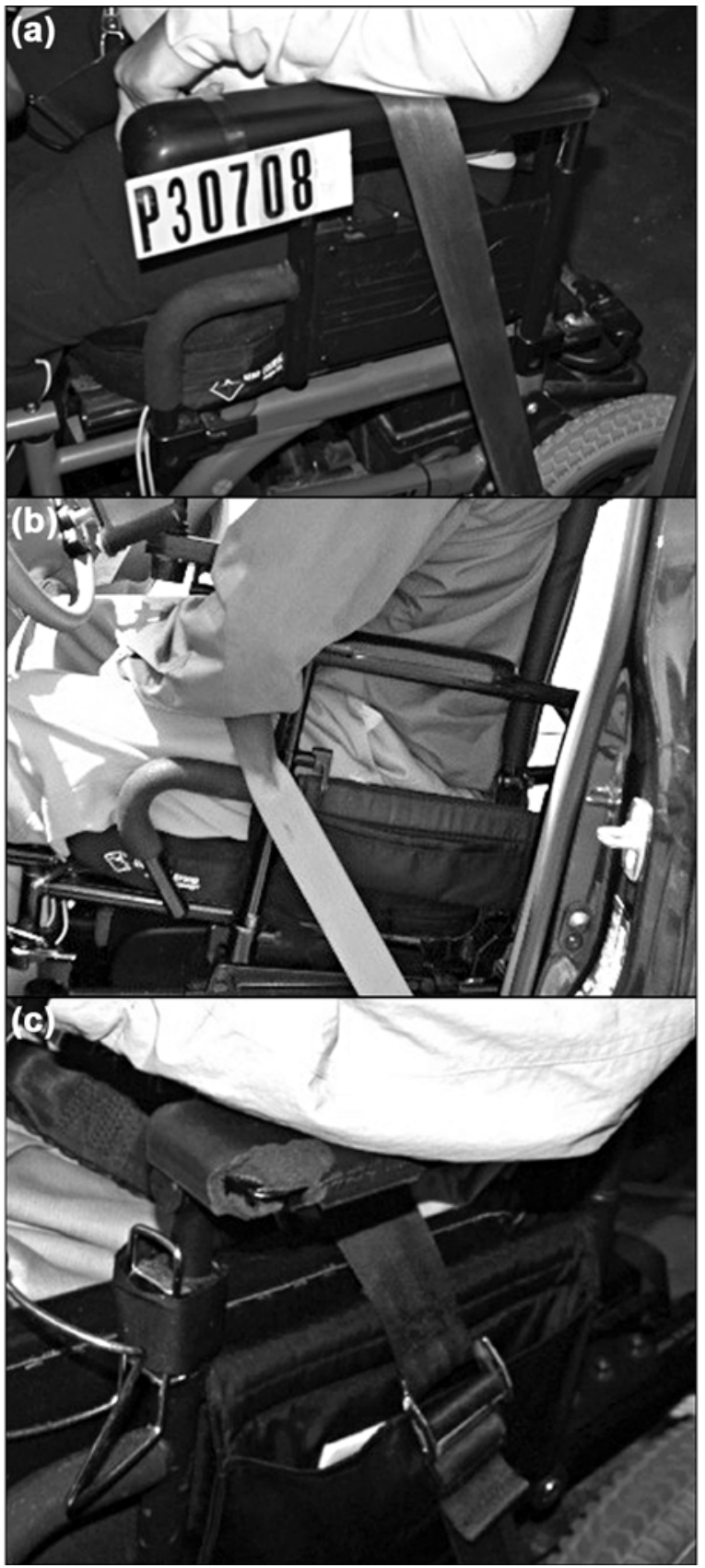

Figure 1.

Photographs showing pelvic seat belt (a) routing over arm supports, (b) across front of arm supports through opening under armrests, and (c) between arm support and back-support posts. belt (Figure 3). Of the 21 wheelchair-seated drivers, 10 actively donned and buckled their seat belts while 8 used a passive seat belt and 3 did not use any seat belt.

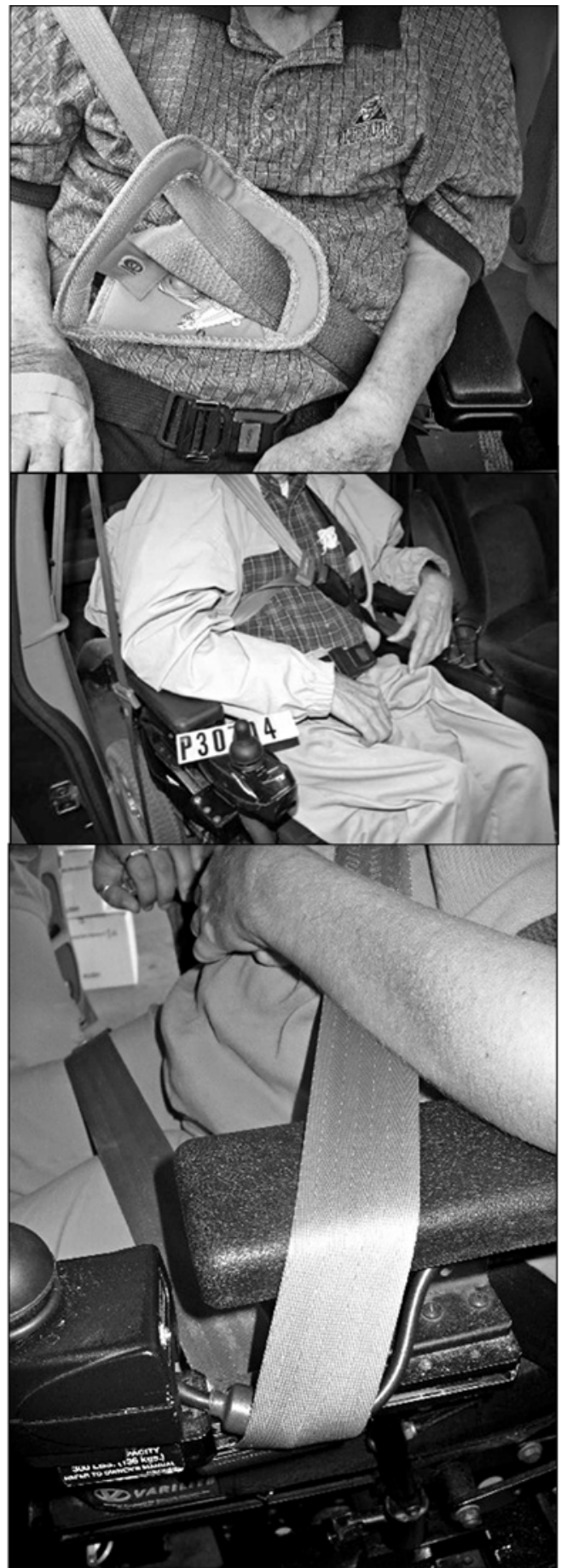

Figure 2.

Observed seat belt misuse by wheelchair-seated passengers. 
We observed several different belt routing configurations. Configurations included belt routing over the top of the wheelchair arm supports $(n=6)$, across the front of the armrests $(n=11)$, through an opening under the arm support $(n=2)$, and between the armrest and wheelchair seatback-support post ( $n=1)$ (Figure 1).

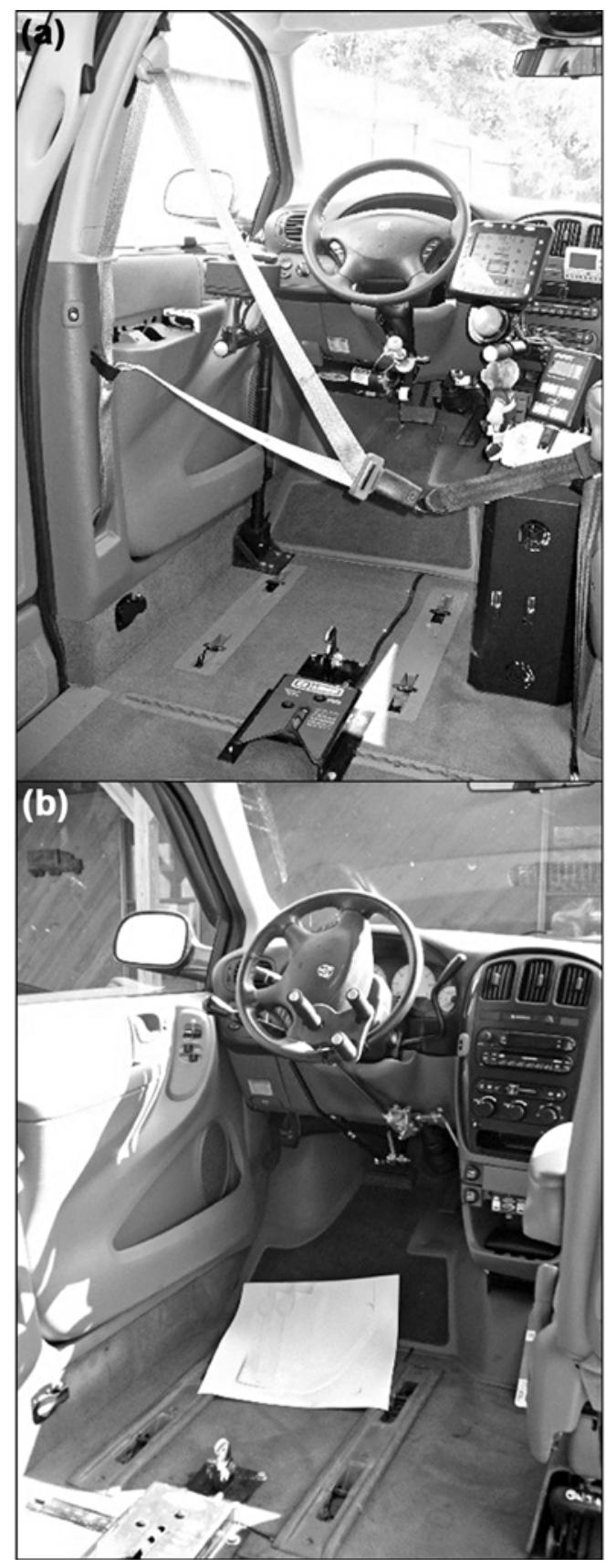

Figure 3.

Example of (a) passive and (b) active wheelchair seat belt restraint system.

\section{Perceived Securement and Seat Belt Usability, Safety, and Independent Use}

Table 7 lists the scores for the usability, safety, and independent use of participants with regard to wheelchair securement, seat belt systems, and their modified vehicle. We again used a 5-point Likert scale to categorize participants' answers.

On average, drivers seated in wheelchairs rated the usability, safety, and independent use of their wheelchair securement systems and their vehicles as "good" or "excellent" and the usability, safety, and independent use of their seat belt systems between "could be better" and "good." On average, wheelchair-seated passengers rated the usability and safety of their securement systems and their vehicles from "could be better" to "good." Securement independence; vehicle independence; and the usability, safety, and seat belt independence were rated, on average, "poor” or "could be better.”

\section{Improvements to Safety}

We asked participants what was missing in their vehicles or on their wheelchairs that could enhance their safety. Five drivers mentioned missing a head and/or back restraint, while eight participants (5 drivers and 3 passengers) missed a postural belt or a seat belt that provides postural support during the ride and a seat belt that was easy to use and comfortable. Three participants (2 drivers and 1 passenger) commented on the need for improved airbag positioning relative to their steering controls and/or driver position, and two drivers indicated the need for improved secondary controls (to operate turn signals, windshield wipers, etc.) that are usable while they are driving with both hands on the hand controls.

Table 7.

Participant ratings for securement and seat belt usability, safety, and independent use, where 1 = don't know, 2 = poor, 3 = could be better, 4 = good, and $5=$ excellent.

\begin{tabular}{lccc}
\hline \multicolumn{1}{c}{ Safety System Rating } & Combined & Driver & Passenger \\
\hline Securement Usability & 4.0 & 4.5 & 3.4 \\
Securement Safety & 3.9 & 4.1 & 3.6 \\
Securement Independence & 3.6 & 4.3 & 2.9 \\
Seat Belt Usability & 3.2 & 3.5 & 2.9 \\
Seat Belt Safety & 3.3 & 3.8 & 2.9 \\
Seat Belt Independence & 3.0 & 3.6 & 2.4 \\
Vehicle Usability & 4.1 & 4.4 & 3.8 \\
Vehicle Safety & 3.9 & 4.1 & 3.6 \\
Vehicle Independence & 3.4 & 4.2 & 2.5 \\
\hline \hline
\end{tabular}


A total of 24 recommendations for improving the vehicle's safety system were provided by drivers, passengers, and passenger caregivers. Three drivers and three passengers refrained from suggesting improvements to their vehicle safety system. Table 8 lists the recommended improvements from the study participants.

\section{Potentially Unsafe Modifications to Vehicle Safety Systems}

Several participants indicated the need for better postural support during driving; a few participants had followed up on these needs and made changes to their seat belt system to enhance postural support but that compromised their safety. One driver had hooked the original vehicle shoulder belt around the wheelchair back-support post to increase postural stability (Figure 4(a)-(b)). This resulted in a poor fit of the lap belt over the abdomen instead of being low on the pelvis and would increase forces on the wheelchair frame in case of an emergency maneuver or vehicle impact. Another driver pulled the seat belt underneath the wheelchair arm support to reduce interference of the shoulder belt (when routed over the upper torso) with forward reach of the driver's left arm (Figure 4(c)). Another driver had pulled the shoulder belt out of the retractor until it was locked and then fixed it to the loose-hanging lap belt (Figure 4(d)) so that the shoulder belt was tight across the chest. Another driver only used the shoulder belt portion of the restraint with a thin chest strap wrapped around the wheelchair for postural support (Figure 4(e)).

Table 8.

Participant-suggested improvements to vehicle safety systems and desired features.

\section{General Improvements to Seat Belt Systems}

1. An ideal occupant restraint system would be waiting out of the way while a wheelchair user enters the station. Then on the push of a button, the belts or harness would retract to a position and tension according to a preset preference.

2. Have a passive restraint system/have a passive system to move shoulder belt into place.

3. Have the belt held up and out of way of the wheelchair entering the station, then move the belt down and into place easily.

4. Have a drive-in lap belt and then you push a switch/control that tightens the belt.

5. I would want a drive-in system. It adjusts up and is located at the pelvis. It allows for pressure relief (repositioning) during the ride.

6. Have a drive-in system.

\section{Improvements to Seat Belt and Securement System Accessibility}

1. Position the inboard buckle closer to the wheelchair so that it's easier to reach.

2. Make the stalk or cable stiffer so it holds the inboard belt up better/raise the buckle post higher so that I don't have to lift the belt up and over my knees when I drive in.

3. Move the anchor points so they are more accessible/make the belts more within reach so that I can use the belt myself instead of relying on my caregiver.

4. Have adjustment of floor-mounted stalks in fore/aft and sideways directions.

5. Design the armrest to be open to facilitate proper seat belt positioning.

6. Design a retractable securement bolt on the wheelchair to better clear obstacles when not in the vehicle.

7. Raise the securement bolt up to increase ground clearance.

8. Allow for more adjustability of the occupant restraints to get around wheelchairs that raise or recline.

\section{Adjustments to Seat Belt Tension and Positioning}

1. Change the postural support to provide more stability during driving.

2. I would like a similar system as I had in my old van. The restraint was bolted to the ceiling and had no play.

3. Make the restraint retractor lock up for a snug fit.

4. Lower the shoulder-belt anchor point so that it doesn't cut my neck.

5. Lighten the retraction in the belt so that it doesn't retract during reclining.

6. Adjust the tension in the belt to meet positioning needs.

\section{Other Restraint Improvements}

1. Make a system like they use in amusement park rides. A bar comes down and is mounted on the wheelchair.

2. Mount and design the restraint so that it doesn’t prevent my arm from reaching the controls.

3. Have adjustable belts to fit all sizes of wheelchairs. 


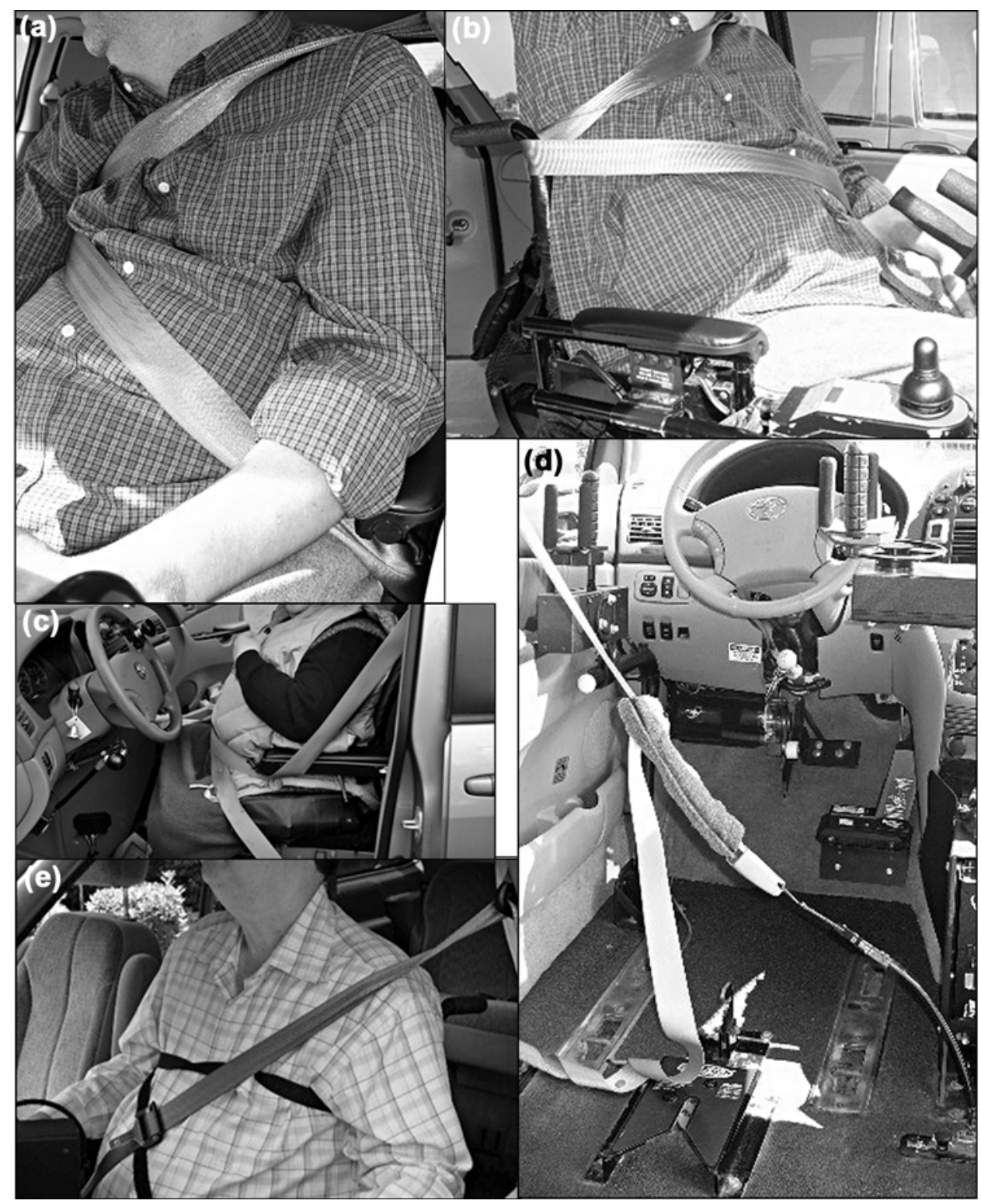

Figure 4.

Examples of unsafe modifications to vehicle safety systems. (a)-(b) Driver hooked original vehicle shoulder belt around wheelchair back-support post to increase postural stability. (c) Driver pulled seat belt underneath wheelchair armrest to reduce interference of shoulder belt (when routed over upper torso) with forward reach of driver's left arm. (d) Driver pulled shoulder belt out of retractor until it was locked and then fixed it to (loose-hanging) lap belt so that shoulder belt was tight across chest. (e) Driver only used shoulder belt portion of restraint with thin chest strap wrapped around wheelchair for postural support.

\section{DISCUSSION}

The objective of this portion of a larger study aimed at quantifying issues related to the safety, usability, and independent use of private vehicles by drivers and front- row passengers seated in wheelchairs was to observe and document the difficulties that these occupants face when using their vehicle and the adaptive equipment. Other objectives of this study were to document the levels of safety, usability, and independence perceived by these 
occupants and to collect ideas from this population of travelers on how to improve safety system design for safer and more independent use in private vehicles.

Vehicles of study participants were equipped to allow riders seated in wheelchairs to independently drive and passengers seated in wheelchairs to ride in the front row of their private vehicles. Because of the relatively small sample of subjects and the fact that there are only a few accredited mobility equipment dealers in the Ann Arbor and Pittsburgh areas, vehicle modifications may not be fully representative of wheelchair-seated drivers and front-row passengers in the United States. Additionally, new vehicles on the market are being equipped with stateof-the-art primary and secondary control system technologies that may not have been available to the study population. The average age of the 17 wheelchair-seated drivers in the study was $47.1 \mathrm{yr}$, which is 11.4 yr younger than the average age of the front-row passengers, whose average age was 58.5 years. The duration of wheelchair and vehicle use was $\sim 5$ yr longer for the drivers than front-row passengers. Drivers also used their vehicles more frequently than passengers ( $5.5 \mathrm{~d} / \mathrm{wk}$ vs $3.0 \mathrm{~d} / \mathrm{wk}$ ).

Results indicate that the usability of the (modified) seat belts and wheelchair securement devices for use by drivers and caregivers could be improved in several ways. Previous studies also support this finding. For example, Linden et al., van Roosmalen and Lane, van Roosmalen et al., and Wretstrand et al. previously reported a need for improved seat belt systems and wheelchair securement systems for use by wheelchair-seated drivers [11-14].

The recommendations that study participants provided are useful and focus on innovative means for improving occupant crash protection that are readily accessible to wheelchair-seated occupants in either power or manual wheelchairs. The recommendations for a seat belt that automatically tightens to help maintain a seated position during normal driving and/or allows for customized belt fit will be useful for those individuals unable to manually adjust or tighten their own seat belt. Other recommendations include a better means for postural support to help riders maintain an upright posture during vehicle turns, during sudden vehicle stops, and when traversing rough terrain. Note that passengers seated in wheelchairs do not need to operate sensitive driving controls and therefore do not need to be as stable (restricted in their posture) as drivers seated in wheelchairs.

Postural belts such as pelvic belts and chest harnesses will not provide adequate protection during a motor vehicle impact; although some postural belts look like automotive seat belts, their anchor points, buckle hardware, and webbing is designed to withstand crash level loading thereby risking injury to the wheelchair occupant in a crash situation. A draft of the voluntary RESNA wheelchair seating standard requires evaluation of postural pelvic supports at a maximum repetitive load of only $750 \mathrm{~N}$ [15]. Pelvic and shoulder belt loads measured during frontal impact loading conditions will grossly exceed these maximum postural belt loads [16].

Current seat belt systems allow for the shoulder belt to spool out from the retractor when a person (slowly) leans forward. For some wheelchair-seated individuals with limited upper-torso control, webbing spool-out is not desired and can result in postural imbalance while driving. Finally, to improve accessibility and independent use of the belt-restraint system, wheelchair users indicated that the buckle receptacle must be within reach at all times. Reed and van Roosmalen investigated the reach capability of wheelchair-seated individuals [17].

Improved seat belt systems are currently being developed by both Q'Straint Worldwide in collaboration with the University of Pittsburgh and the University of Michigan. Prototype designs have incorporated the recommendations from participants in this study. The prototypes allow a wheelchair-seated individual to drive into a passive vehicle-anchored pelvic/shoulder-belt restraint. The Q'Straint-UPITT product, called the Drive-In-OccupantRestraint (DIOR), includes an optional fixed-length shoulder belt that can be used for drivers seated in wheelchairs that do not have a torso support on their wheelchair but wish to rely on a (nonretractable) vehicle-mounted shoulder belt for torso support. The pelvic belt portions of the Q'Straint-UPITT product and the University of Michigan prototype system are both automatically positioned around a wheelchair-seated user while he or she moves into the driver station.

\section{CONCLUSIONS}

The findings of this study will be used to educate practitioners in the field on the importance of achieving improved safety, usability, and independence when modifying motor vehicles for drivers and front-row passengers seated in wheelchairs. The findings will also be used to develop better technologies for those who stay seated in their wheelchairs while driving a personal vehicle. 


\section{ACKNOWLEDGMENTS}

\section{Author Contributions:}

Study concept and design: L. van Roosmalen, L. Schneider, N. Ritchie Orton.

Acquisition, analysis, and interpretation of data: L. van Roosmalen, N. Ritchie Orton.

Drafting of manuscript: L. van Roosmalen.

Critical revision of manuscript for important intellectual content:

L. van Roosmalen, L. Schneider.

Statistical analysis: L. van Roosmalen.

Obtained funding: L. van Roosmalen, L. Schneider.

Administrative, technical, or material support: L. van Roosmalen, L. Schneider.

Study supervision: L. van Roosmalen.

Financial Disclosures: The authors have declared that no competing interests exist.

Funding/Support: This material was based on work supported by the Rehabilitation Engineering Research Center on Wheelchair Transportation Safety (grant H133E060064), which is funded by the National Institute on Disability and Rehabilitation Research and the Department of Education.

Additional Contributions: Dr. van Roosmalen has left the University of Pittsburgh to found LINC Design LLC, Verona, Pennsylvania, where she continues her research on wheelchair transportation safety. Institutional Review: Institutional review board approval for the study was obtained from the University of Pittsburgh (PRO07010083) and University of Michigan (HUM00014418).

Participant Follow-up: The authors do no plan to inform participants of the publication of this study. However, participants have been encouraged to check the study Web site for updated publications.

Disclaimer: The opinions expressed herein are those of the authors and are not necessarily reflective of those of the funding agency.

\section{REFERENCES}

1. U.S. Bureau of Transportation Statistics. Freedom to travel. Washington (DC): U.S. Department of Transportation; 2003.

2. Cowen A, Durant S. Research note: Common vehicle modifications for persons with disabilities [Internet]. Washington (DC): U.S. Bureau of Transportation Statistics; [2002 Sep]. Available from: http://www.nhtsa.gov/cars/rules/adaptive/BTSRN/ ResearchNote0209.html

3. Society of Automotive Engineers. SAE J2249: Wheelchair tiedown and occupant restraint systems for use in motor vehicles. Warrendale (PA): Society of Automotive Engineers; 1999.

4. van Roosmalen L, Bertocci GE, Hobson DA, Karg P. Preliminary evaluation of wheelchair occupant restraint system usage in motor vehicles. J Rehabil Res Dev. 2002; 39(1):83-93. [PMID:11926330]
5. U.S. Department of Transportation. FMVSS crash protection systems. Washington (DC): U.S. Department of Transportation; 1993.

6. Bertocci GE, Digges KH, Hobson DA. Shoulder belt anchor location influences on wheelchair occupant crash protection. J Rehabil Res Dev. 1996;33(3):279-89. [PMID:8823675]

7. National Highway Traffic Safety Administration. FMVSS 208 occupant crash protection. Vol. 49 CFR 571.208. Washington (DC): U.S. Department of Transportation; 1993.

8. Schneider LW, Manary MA. Wheelchairs, wheelchair tiedowns, and occupant restraints for improved safety and crash protection. In: Pellerito JM, editor. Driver rehabilitation and community mobility: Principles and practice. St. Louis (MO): Elsevier Mosby; 2006.

9. ANSI/RESNA. ANSI/RESNA WC-19: A voluntary standard for wheelchairs used as seats in motor vehicles. Arlington (VA): ANSI/RESNA; 2001.

10. Ritchie N, Manary MA, van Roosmalen L, Schneider LW. The role of armrest design in positioning of belt restraints on wheelchair-seated drivers. RESNA Annual Conference; 2009 Jun 23-27; New Orleans, LA. Washington (DC): RESNA Press; 2009.

11. Linden MA, Kamper DG, Reger SI, Adams TC. Transportation needs: Survey of individuals with disabilities. Proceedings of the 19th Annual RESNA Conference; 1996 Jun 712; Salt Lake City, UT. Washington (DC): RESNA Press; 1996. p. 52-54.

12. van Roosmalen L, Lane A. Driving with a disability-Clinical and technical perspectives. Proceedings of the 25th International Seating Symposium; 2009 Mar 12-14; Orlando, FL. p. 157-58.

13. van Roosmalen L, Lutgendorf M, Manary MA. Occupant restraint preferences of individuals traveling in motor vehicles while seated in their wheelchairs. Assist Technol. 2008; 20(4):181-93. [PMID:19160905] http://dx.doi.org/10.1080/10400435.2008.10131945

14. Wretstrand A, Petzäll J, Ståhl A. Safety as perceived by wheelchair-seated passengers in special transportation services. Accid Anal Prev. 2004;36(1):3-11. [PMID:14572821] http://dx.doi.org/10.1016/S0001-4575(02)00108-2

15. RESNA. RESNA WC-3: Postural support devices. Test methods for static, impact and repeated load strength. Arlington (VA): RESNA Press; 2010.

16. VanRoosmalen L, Bertocci GE, Ha D, Karg P. Wheelchair integrated occupant restraints: feasibility in frontal impact. Med Eng Phys. 2001;23(10):687-98. [PMID:11801410] http://dx.doi.org/10.1016/S1350-4533(01)00082-0

17. Reed MP, van Roosmalen L. A pilot study of a method for assessing the reach capability of wheelchair users for safety belt design. Appl Ergon. 2005;36(5):523-28.

[PMID:15939393] http://dx.doi.org/10.1016/j.apergo.2005.04.002 
Submitted for publication November 18, 2011. Accepted in revised form June 21, 2012.

This article and any supplementary material should be cited as follows:

van Roosmalen L, Ritchie Orton N, Schneider L. Safety, usability, and independence for wheelchair-seated drivers and front-row passengers of private vehicles: A qualitative research study. J Rehabil Res Dev. 2013;50(2):239-52.

http://dx.doi.org/10.1682/JRRD.2011.11.0217

ResearcherID: Linda van Roosmalen, PhD: B-7909-2013

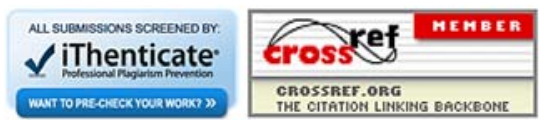


